\title{
THE THERMAL AND PRECIPITATION CONDITIONS DURING THE WINTER SEASONS IN POLAND
}

Among all the seasons of the year winter features the greatest variability of atmospheric conditions. Polish winters may feature long periods of frosty weather, but there also occur the ones during which practically no frost happens. The last decade brought the series of three consecutive exceptionally warm winters, as well as one of the two longest winters of this century.

The purpose of the present paper is to show: 1) the range of variability of temperature during winter; 2) the connection between thermal and precipitation conditions occurring during winter; as well as 3 ) the character of atmospheric circulation during winter months and whole winter seasons with anomalous thermal and/or precipitation conditions.

The analysis was carried out for the example of Warsaw. The data used consisted of the monthly average series of temperature and precipitation sums for the 100 year period of 1870/71-1969/70, as recorded at the weather station of Warsaw-Astronomical Observatory, located in downtown Warsaw, as well as the series from the periods 1932/1933-1996/97 (temperature only) and 1950/51-1996/97 (temperature and precipitation) taken at the station Warsaw-Okęcie, located within Warsaw airfield in the southwestern peripheries of the town. During the two decades (1951-1970) which are common for the two time series the average winter temperature in the downtown station was higher by $0.3^{\circ} \mathrm{C}$ and precipitation was higher by 38 $\mathrm{mm}$ (i.e. $47 \%$ ) in comparison with the peripheral station of Okęcie.

During the 100-year period of 1871-1970 the average winter temperature, i.e. for the months from December to February, was $-2.3^{\circ} \mathrm{C}$ and ranged between $-8.8^{\circ} \mathrm{C}(1939 / 40)$ and $+1.0^{\circ} \mathrm{C}(1909 / 1910$ and $1924 / 25)$, while in the second time series, 1933-1997, the respective values were as follows: $-2.1^{\circ} \mathrm{C},-9.1^{\circ} \mathrm{C}(1939 / 40)$ and $+2.5^{\circ} \mathrm{C}(1989 / 90)$. Thus, the range of variability of temperatures was bigger during the second period considered, which was connected with appearance of the warm winters at the end of $1980 \mathrm{~s}$.

The range of variability of average temperature in consecutive months was much bigger than for the whole season, and the greatest variability was observed for February, with values ranging between $-13.9^{\circ} \mathrm{C}$ (1929) and $+4.7^{\circ} \mathrm{C}(1990)$ - see Table 4 . If we order winter months from the 
coldest to the warmest then the average situation is: January-FebruaryDecember, which we can represent by the abbreviation JFD. It turns out, in terms of frequency, that this type is in fact the most often encountered, but the winter types FJD and JDF are not much less frequent (Table 1). These types account for altogether $70 \%$ of winters. For more than half of winters January is in fact the coldest month and/or the warmest is December, though the opposite situations occur as well, with, however, January being the least frequently the warmest month (FDJ and DFJ types).

Table 1

Frequencies of the distinguished winter types and the average monthly temperatures in particular types

\begin{tabular}{|c|c|c|c|c|c|c|c|c|c|c|}
\hline \multirow{3}{*}{ 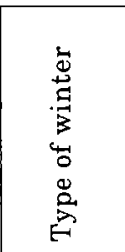 } & \multicolumn{5}{|c|}{$\begin{array}{c}\text { Astronomical Observatory } \\
1870 / 71-1969 / 70\end{array}$} & \multicolumn{5}{|c|}{$\begin{array}{c}\text { Okęcie } \\
\text { 1932/33-1996/97 }\end{array}$} \\
\hline & \multirow{2}{*}{ 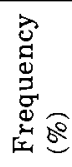 } & \multicolumn{4}{|c|}{ Temperature $\left({ }^{\circ} \mathrm{C}\right)$} & \multirow{2}{*}{ 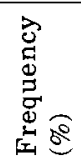 } & \multicolumn{4}{|c|}{ Temperature $\left({ }^{\circ} \mathrm{C}\right)$} \\
\hline & & $\mathrm{D}$ & $J$ & $\mathrm{~F}$ & Winter & & D & $J$ & $\mathbf{F}$ & Winter \\
\hline average & - & - & $-1,5$ & $-3,3$ & $-2,3$ & $-2,3$ & - & $-0,9$ & $-3,3$ & $-2,2$ \\
\hline $\mathrm{JFD}$ & 25,5 & $-0,0$ & $-5,6$ & $-2,3$ & $-2,7$ & 31 & $-0,4$ & $-6,3$ & $-2,5$ & $-3,1$ \\
\hline FJD & 25 & $-0,5$ & $-2,5$ & $-4,9$ & $-2,6$ & 20 & $-0,2$ & $-2,6$ & $-5,9$ & $-2,9$ \\
\hline JDF & 20,5 & $-2,0$ & $-4,6$ & $-0,5$ & $-2,4$ & 21 & $-1,2$ & $-3,5$ & 0,4 & $-1,4$ \\
\hline DJF & 14,5 & $-4,1$ & $-1,8$ & $-0,3$ & $-2,0$ & 13 & $-3,3$ & $-1,5$ & 0,6 & $-1,4$ \\
\hline FDJ & 6 & $-0,1$ & 0,8 & $-2,4$ & $-0,6$ & 11 & 0,6 & 1,3 & $-2,4$ & $-0,2$ \\
\hline DFJ & 8,5 & $-3,4$ & $-0,3$ & $-2,1$ & $-1,9$ & 4 & $-3,5$ & $-0,9$ & $-2,8$ & $-2,3$ \\
\hline
\end{tabular}

Individual winter types differ as to the thermal conditions. Temperatures are the lowest during the most frequent (and the average) type JFD, and only slightly higher during the FJD type winters. The decidedly warmest are the FDJ type winters, whose proportion distinctly increased during the last 20 years. On the average, the coldest month is January during JFD type winters (approximately $-6^{\circ} \mathrm{C}$ ), and the warmest - also January, during FDJ winters (approximately $+1^{\circ}$ ), see Table 1 .

The average temperatures in the winter months, from the coldest to the warmest, irrespective of which month it was, were in the period 1871-1970 as follows: $-4.7,-2.1$ and $-0.2^{\circ} \mathrm{C}$, while in the period 1933-1997: $-4.7,-1.8$, and $0.0^{\circ} \mathrm{C}$.

Attention should also be paid to the fact that there are individual years during which the coldest month is November or March, and so, for instance, in the period 1933-1997 each of these two months was the coldest twice (November in the seasons 1988/89 and 1993/94, March in 1951/52 and $1957 / 58$ ). In three out of the four seasons mentioned the average temperature of the coldest month was negative. In terms of air temperature, winter is defined in Poland as the period during which daily average falls below $0^{\circ} \mathrm{C}$. This means that thermal winter does not exactly coincide with the 
period between December and February. Thus, in the period 1932/33- 1996/97 thermal winter started on the average on December 9th and ended on March $2 \mathrm{nd}$, with average duration of 84 days. It started the earliest on November 7 th (in 1993), and ended the latest on March 28th (1942 and 1958), yielding the potential maximum winter duration of 142 days. The actually longest winter lasted for 140 days (1941/42 - between November 9th and March 28th), followed by the winter which lasted for 129 days (1995/96 — from November 14th till March 21st), while during three seasons (1987/88, 1988/89 and 1989/90) thermal winter did not occur at all. In some seasons thermal winter was intermitted with the thaws, and so, for instance, during the season of 1993/94 thermal winter lasted since November 7th until December 3rd (27 days) and then again between January 29 th and February 26 th (29 days), i.e. two winter periods lasting altogether 56 days were separated by a period with positive temperatures, lasting exactly the same length of 56 days.

Individual winters differ also significantly as to precipitation. During the period 1870/71-1969/70 the average precipitation during the seasons extending from December to February was $98 \mathrm{~mm}$; the lowest precipitation values were $37 \mathrm{~mm}(1889 / 90)$ and $38 \mathrm{~mm}(1881 / 82)$, while the highest: 171 $\mathrm{mm}$ (1966/67), $166 \mathrm{~mm}(1954 / 55)$ and $165 \mathrm{~mm}(1969 / 70)$. In the period 1950/51 - 1996/97 the respective values were: $79 \mathrm{~mm}$ - average, $28 \mathrm{~mm}$ (1996/97), $29 \mathrm{~mm}(1962 / 63)$, and $31 \mathrm{~mm}(1968 / 69)$ - the lowest, $139 \mathrm{~mm}$ (1966/67) - the highest.

In order to state whether there is any relation between temperature and precipitation, classification was performed of all the winter months and the whole seasons into three groups of the same (in practice: very similar) numbers of elements, according to the increasing temperature: below the norm, at norm, and above the norm. Similar classification was carried out for months and seasons according to precipitation. Then, each month and season was assigned to the respective thermal-and-precipitation category. Every month in the periods $1870 / 71-1969 / 70$ and 1950/51-1996/97 was considered separately.

It was stated that there are months and seasons corresponding to each of the thus established categories. Temperature below the norm is most often accompanied by precipitation below the norm, while temperature above the norm - by precipitation at norm or above, while the least frequent are the months and seasons of the opposite thermal and precipitation categories. This pattern of incidence is most pronounced in February, and least pronounced in January; it is also significant for the whole season (see Table 2). The result obtained was subject to $\chi^{2}$ test. On the basis of the value of the $\chi^{2}$ statistic it was concluded that the probability of the chance occurrence of such a pattern of incidence is $1-2 \%$.

The determined nature of thermal-precipitation relations finds also a clear reflection in the average values of temperature and precipitation of the seasons belonging to various categories. And so, in the period 1950/51$1996 / 97$ during cold and dry winters the average temperature was equal $-4.6^{\circ} \mathrm{C}$, during cold and wet winters: $-3.9^{\circ} \mathrm{C}$, during warm and dry winters: 
Table 2

Numbers of winter months and seasons belonging to various thermal and precipitation categories

\begin{tabular}{|c|c|r|r|}
\hline \multicolumn{4}{c}{ Astrono } \\
\hline $\mathrm{p} \backslash \mathbf{t}$ & - & $\mathrm{n}$ & + \\
\hline- & 11 & 15 & 7 \\
\hline $\mathrm{n}$ & 17 & 4 & 14 \\
\hline+ & 6 & 16 & 10 \\
\hline
\end{tabular}

$\chi^{2}=14,96$

\begin{tabular}{|r|r|r|r|}
\hline $\mathrm{p} \backslash \mathrm{t}$ & - & $\mathrm{n}$ & + \\
\hline- & 14 & 8 & 11 \\
\hline $\mathrm{n}$ & 15 & 8 & 1 \\
\hline+ & 4 & 17 & 12 \\
\hline
\end{tabular}$\quad \chi^{2}=11,72$

Okęcie 1950/51-1996/97

\begin{tabular}{|}
\begin{tabular}{|c|c|c|c|}
\hline $\mathrm{p} \backslash \mathrm{t}$ & - & $\mathrm{n}$ & + \\
\hline- & 6 & 8 & 1 \\
\hline $\mathrm{n}$ & 8 & 4 & 5 \\
\hline+ & 1 & 5 & 9 \\
\hline
\end{tabular}
\end{tabular}

$\chi^{2}=13,26$

\begin{tabular}{|c|c|c|c|}
\hline $\mathrm{p} \backslash \mathrm{t}$ & - & $\mathrm{n}$ & + \\
\hline- & 11 & 4 & 2 \\
\hline $\mathrm{n}$ & 1 & 5 & 8 \\
\hline+ & 4 & 5 & 7 \\
\hline
\end{tabular}

$\chi^{2}=13,22$

$\mathrm{t}$ - temperature, $\mathrm{p}$ - precipitation, -- below normal, $\mathrm{n}-$ at norm, +- above normal.

Table 3

Numbers of winter months and seasons normal and anomalous in thermal and precipitation terms

Astronomical Observatory 1870/71-1969/70

\begin{tabular}{|c|c|c|c|c|c|}
\hline & ec & vc & c & n & w \\
\hline vd & - & - & - & & - \\
d & 1 & 2 & 4 & 13 & 3 \\
n & - & 1 & 8 & 45 & 9 \\
r & - & - & - & 7 & 3 \\
vr & - & - & - & 2 & 1 \\
\hline
\end{tabular}

\begin{tabular}{|c|c|c|c|c|}
\hline & wc & c & $\mathrm{n}$ & $\mathrm{w}$ \\
\hline $\mathrm{vd}$ & - & - & 3 & - \\
$\mathrm{d}$ & 2 & 1 & 12 & 2 \\
$\mathrm{n}$ & 3 & 7 & 46 & 7 \\
$\mathrm{r}$ & - & 1 & 14 & 2 \\
\hline
\end{tabular}

Okęcie 1950/51-1996/97

\begin{tabular}{|c|c|c|c|c|c|}
\hline & ec & vc & c & n & w \\
\hline $\mathrm{d}$ & - & 3 & 2 & 7 & - \\
$\mathrm{n}$ & 1 & - & 3 & 19 & 3 \\
$\mathrm{r}$ & - & - & - & 6 & 2 \\
$\mathrm{vr}$ & - & - & - & - & 1 \\
\hline
\end{tabular}

February

\begin{tabular}{|c|c|c|c|c|}
\hline & $\mathrm{vc}$ & $\mathrm{c}$ & $\mathrm{n}$ & $\mathrm{w}$ \\
\hline $\mathrm{vd}$ & - & - & 1 & - \\
$\mathrm{d}$ & $\mathbf{1}$ & - & 7 & - \\
$\mathrm{n}$ & 2 & 3 & 22 & $\mathbf{5}$ \\
$\mathrm{r}$ & - & - & 3 & 2 \\
$\mathrm{vr}$ & - & - & 1 & - \\
\hline
\end{tabular}

\begin{tabular}{|c|c|c|c|c|}
\hline & vc & c & n & w \\
\hline vd & - & - & 1 & - \\
d & 1 & 1 & 6 & 1 \\
$\mathrm{n}$ & 1 & 2 & 25 & 2 \\
r & - & 1 & 4 & 2 \\
\hline
\end{tabular}

\begin{tabular}{|c|c|c|c|c|}
\hline \multicolumn{5}{|c|}{ Winter } \\
\hline & vc & c & n & w \\
\hline d & 1 & 5 & 5 & - \\
n & 1 & 2 & 19 & 4 \\
r & - & 1 & 6 & 2 \\
vr & - & - & 1 & - \\
\hline
\end{tabular}

Notation of the thermal/precipitation categories of months and winters: ec - extremely cold, vc - very cold, $\mathrm{c}$ - cold, $\mathrm{n}$ - normal, w - warm, $\mathrm{r}$ - wet (or rainy), vr - very wet 
$-0.6^{\circ} \mathrm{C}$, and during warm and wet winters: $+0.2^{\circ} \mathrm{C}$; on the other hand, during cold and dry winters precipitation amounted on the average to $44 \mathrm{~mm}$, while during warm and dry winters - to $59 \mathrm{~mm}$. Thus, we can state that even within the same thermal category temperature in winter is higher when precipitation is higher. Analogously, in a given precipitation category increase of temperature is accompanied by increase of precipitation.

In the analysis of kinds and frequencies of months and seasons which are anomalous with respect to thermal conditions these were assumed to be "normal" for which temperature differed from the multiannual average by at most 1 standard deviation $(t \pm \sigma)$. The months and seasons with divergence of up to $2 \sigma$ were referred to as cold (negative divergence) or warm (positive divergence), when difference was between $2 \sigma$ and $3 \sigma$ - they were referred to as very cold (no very warm ones were observed), and beyond $3 \sigma$ - as extremely cold. Similar classification was applied to precipitation, and so normal, dry, wet, very dry and very wet months and seasons were distinguished. The double value of standard deviation was used, separately for the negative divergences $\left(\sigma_{-}\right)$and for the positive ones $\left(\sigma_{+}\right)$.

On the basis of the classification presented more than $40 \%$ of all the winter months and seasons ought to be considered normal both in thermal and precipitation terms. The extreme negative divergences of temperature are much bigger than the positive counterparts: the negative ones sporadically exceed even $3 \sigma$, while the positive ones do not exceed $2 \sigma$. Besides this, the cold and very cold months and seasons are usually more frequent that the warm ones.

The cold and very cold months and seasons have precipitation at norm or are dry, while the warm months and seasons have either normal precipitation or are wet. In the 100-year series only one cold and wet winter was noted, and two warm and dry ones, while in the 47-year sequence - only one cold and wet winter, but as many as six cold and very cold winters, which were simultaneously dry (Table 3). The quantitative characteristics of the extremely anomalous months and seasons from the current century are shown in Table 4.

The thermal and precipitation conditions of any location depend upon the character of atmospheric circulation. During winters in Poland the dominating types of circulation appear intermittently and are quite opposite as to their direction and nature (according to the classification of B.Osuchowska- Klein, 1978, 1991). These two are, on the one hand: the eastern and south-eastern anticyclonal circulation (15\% of winter days), connected with the wedge of the Asian high pressure area, and, on the other hand, the north-western cyclonal circulation (13\%), connected with the low pressure area over Baltic Sea. Besides this, quite frequently encountered are other cyclonal types from the western sector: south-western $(12 \%)$ and western $(11 \%)$, as well as anticyclonal north-eastern (10\%). 
Winter months and seasons featuring the highest degree of thermal and/or precipitation anomaly in Warsaw in the period 1900/01-1996/97

\begin{tabular}{|c|c|c|c|c|c|c|c|}
\hline \multicolumn{4}{|c|}{ Astronomical Observatory } & \multicolumn{4}{|c|}{ Okęcie } \\
\hline 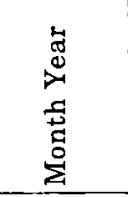 & 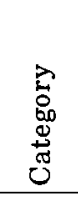 & 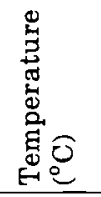 & 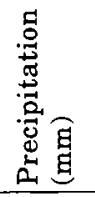 & 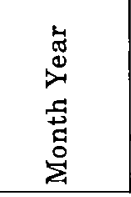 & 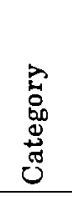 & 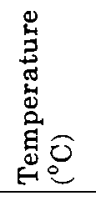 & 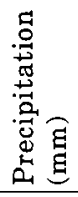 \\
\hline \multicolumn{4}{|c|}{ December } & \multicolumn{4}{|c|}{ December } \\
\hline 1927 & cvd & -5.8 & 3 & 1954 & wvr & 2.7 & 76 \\
\hline 1954 & wvr & 2.6 & 92 & 1963 & ved & -5.2 & 12 \\
\hline 1960 & wn & 3.0 & 34 & 1969 & ecn & -8.5 & 23 \\
\hline 1969 & $\operatorname{ven}$ & -8.2 & 54 & 1971 & wn & 3.1 & 28 \\
\hline \multicolumn{4}{|c|}{ January } & 1984 & nd & -1.3 & 7 \\
\hline 1905 & nvr & -4.4 & 74 & 1995 & ved & -5.3 & 16 \\
\hline 1921 & wvr & 2.6 & 72 & 1996 & ved & -5.4 & 6 \\
\hline 1940 & $\operatorname{ven}$ & -12.1 & 42 & \multicolumn{4}{|c|}{ January } \\
\hline 1942 & ved & -10.9 & 14 & 1963 & ved & 12.4 & 3 \\
\hline 1963 & ved & -11.9 & 15 & 1983 & wr & 3.2 & 38 \\
\hline 1964 & nvd & -3.0 & 1 & 1987 & ven & -12.3 & 14 \\
\hline \multicolumn{4}{|c|}{ February } & 1993 & $\mathrm{nr}$ & 0.1 & 48 \\
\hline 1914 & wd & 1.4 & 5 & 1997 & nvd & -4.4 & 1 \\
\hline 1925 & wn & 3.4 & 24 & \multicolumn{4}{|c|}{ February } \\
\hline 1929 & ecn & -13.9 & 24 & 1956 & ven & -12.2 & 23 \\
\hline 1947 & ver & -10.8 & 60 & 1976 & nvd & -4.2 & 0 \\
\hline 1956 & ver & -11.7 & 47 & 1977 & nvr & 0.5 & 56 \\
\hline 1958 & $\mathrm{nr}$ & 0.0 & 72 & 1986 & ved & -9.6 & 7 \\
\hline \multicolumn{4}{|c|}{ Winter } & \multicolumn{4}{|c|}{ Winter } \\
\hline $1904 / 05$ & $\mathrm{nr}$ & -1.5 & 167 & $1962 / 63$ & ved & -8.2 & 29 \\
\hline $1909 / 10$ & wn & 1.0 & 79 & $1966 / 67$ & nvr & -1.5 & 139 \\
\hline $1918 / 19$ & nvd & -1.2 & 43 & $1988 / 89$ & wn & 2.3 & 80 \\
\hline $1924 / 25$ & wd & 1.0 & 66 & $1989 / 90$ & wn & 2.5 & 69 \\
\hline $1928 / 29$ & $\mathrm{ven}$ & -7.7 & 82 & $1996 / 97$ & nd & -2.7 & 28 \\
\hline $1939 / 40$ & ven & -8.8 & 91 & & & & \\
\hline $1946 / 47$ & $\operatorname{ven}$ & -7.5 & 96 & & & & \\
\hline $1954 / 55$ & $\mathrm{nr}$ & -0.9 & 166 & & & & \\
\hline $1962 / 63$ & ved & -7.7 & 63 & & & & \\
\hline $1966 / 67$ & $\mathrm{nr}$ & -1.4 & 171 & & & & \\
\hline
\end{tabular}

The analysis of frequency of appearance of circulation types in anomalous months and seasons showed that the increased share of both the anticyclonal circulations mentioned, as well as persistence a high pressure area with center above Poland are conducive to particularly low temperatures. Thus, for instance, during the coldest December of 1969 (Table 4) their share was $61 \%$ (while the average was 26\%), and in the coldest February of 
1929 even up to $83 \%$ (average share being 30\%). Significant drops of temperature are also connected with the anticyclonal north-western circulation, like, for instance, in the very cold January of 1963, when this type occurred during $35 \%$ of the month (while the average was $2.5 \%$ ), or in February 1986, when it constituted $14 \%$ (4\% on the average), though in the latter case it appeared together with the anticyclonal types from the eastern sector $-68 \%$ ( $24 \%$ on the average). In the coldest months precipitation is usually below normal. Somewhat higher precipitation (though still within the norm) occurs during the months with domination of circulation from the eastern sector, but also of the cyclonal type. Thus, for instance, in the very cold January of 1940 their share was $68 \%$ ( $33 \%$ on the average), the north-eastern and eastern cyclonal types taking together as much as $29 \%$ (9\% on the average). During the very cold and dry winter of $1962 / 63$ the days with anticyclonal circulation from the eastern and northern sector, as well as the central one (high pressure over Poland) constituted $56 \%$ (31\% on the average), and the days with cyclonal north-eastern and eastern circulation constituted $12 \%$ ( $8 \%$ on the average), while during the very cold winter with normal precipitation - $1939 / 40$ - the respective shares were $41 \%$ and $24 \%$.

Appearance of high temperatures in winter is connected with the cyclonal circulation types from the western sector, and especially the southwestern circulation. In the warmest winter month - February 1990 (see Table 4) - the days with south-western, cyclonal and anticyclonal, circulation constituted $64 \%$ ( $14 \%$ on the average), and in the only slightly colder February of 1989 they constituted $29 \%$, with generally western circulation accounting for $46 \%$ of days ( $17 \%$ on the average). During the warm December of 1971 the types of circulation from the sectors ranging from South to West accounted for $64 \%$ of days (37\% on the average), and during warm January of 1983 - for $55 \%$ ( $38 \%$ on the average), with the days when cyclonal north-western circulation occurred accounting for $39 \%$ (as compared to the average of $14 \%$ ). The high share of the latter caused that this was simultaneously the month with high precipitation. Similarly in the warm and very rainy January of 1921 circulations from the sectors raning from South to North-West exclusively occurred, with cyclonal ones accounting for $87 \%$ of days. Likewise, in the warm and rainy January of 1983 the cyclonal western and north-western circulations occurred during $74 \%$ of days (26\% on the average). During the warmest winter of $1989 / 90$ circulation from the western sector accounted for $67 \%$ of days (49\% on the average), and within this share - the south-western circulation accounted for $40 \%$ ( $18 \%$ on the average).

Similarly as in the cold months and seasons, also in the warm ones precipitation depends upon the frequency of cyclonal and anticyclonal circulation types. Domination of cyclonal types is advantageous for higher precipitation, with the highest precipitation levels corresponding to the north-western and southern circulations. Thus, for instance, during the winter with the highest precipitation (1966/67 — see Table 4) the frequen- 
cies of these two types accounted for, respectively, $17 \%$ and $16 \%$ (13\% and $7 \%$, respectively, on the average), while the frequency of all the cyclonal types from the sectors ranging from South to North-West amounted to $50 \%$. The rarely occurring warm and dry months and winters feature high shares of circulations from the southern sector, especially anticyclonal ones. In particular, during warm and dry winter of 1924/25 the anticyclonal southern and south-western type accounted for $17 \%$ of days (4\% on the average), the eastern and south-eastern for $19 \%$ (15\% on the average), while anitcyclonal circulation from the northern sector occurred very seldom (only $4 \%$, while the average is $13 \%$ ).

The analysis of the relations between the thermal and precipitation conditions and the circulation types explains many of the characteristic features of the winter season in Poland:

- air temperature depends upon the direction of circulation: circulations from the eastern and northern sectors cause masses of cold air to come, while circulations from the western and southern sectors bring the masses of warm air;

- the sums of precipitation depend upon the nature of circulation: the anticyclonal circulation linked with high pressure conditions is not conducive to development of clouds and appearance of precipitation, while cyclonal circulation is;

- since during winters in Poland the intermittently dominating types are the anticyclonal eastern and the cyclonal western ones, it is most often so that the cold periods are simultaneously dry, while the warm ones bring increased precipitation;

- persisting advection of the cold air masses, linked with anticyclonal circulation from the eastern or northern sector, leads sometimes to very strong drops of temperature, additionally amplified by the night cooling due to radiation in conditions of cloudless weather, and this is why the extreme anomalous negative temperatures diverge much more from the averages than the positive extremes;

- since the atmospheric circulation at moderate latitudes - including Poland - is highly variable in time, winters in Poland are also characterized by the very high variability of temperature and precipitation, of the temperature pattern during the season, and of the length of the period with negative temperatures.

\section{REFERENCES}

Osuchowska-Klein B., 1978, Katalog typów cyrkulacji atmosferycznej (Catalogue of Atmospheric Circulation Types; in Polish), WKiŁ, Warszawa.

Osuchowska-Klein B., 1991, Katalog typów cyrkulacji atmosferycznej (19761990) (Catalogue of Atmospheric Circulation Types (1976-1990); in Polish), IMGW, Warszawa. 